Plant Tissue Cult. \& Biotech. 27(1): 33-39 (June)

$\overline{\text { PTC\&B }}$

\title{
Molecular Characterization of Tropical Strawberry Genotypes
}

\author{
M.A. Sweety, M.M. Hossain, M.A. Hoque, M. Hasan ${ }^{1}$, N.A. Ivy ${ }^{1}$, \\ M.N. Islam ${ }^{2}$, R.H. Sarker ${ }^{2}$ and S. Mitra ${ }^{3}$ \\ Department of Horticulture, Bangabandhu Sheikh Mujibur Rahman Agricultural \\ University, Gazipur-1706, Bangladesh
}

Key words: Dendrogram, Electrophoresis, Polymorphic marker

\begin{abstract}
Genetic variability of tropical strawberry genotypes was determined through Ramdom Amplified Polymorphic DNA (RAPD) primers. Out of 14 RAPD primers six showed reproducible and polymorphic bands. The results revealed that the maximum polymorphic bands were produced by the primer OPB 12 . Ten genotypes were differentiated into two clusters on the basis of Unweighted Pair Group Method With Arithmetic Averages (UPGMA). Genotypic variation based on molecular characterization indicated that genotypes belonging to two different clusters depend on their genetic component. So, selection of parents from different clusters will provide the maximum heterosis in yield.
\end{abstract}

\section{Introduction}

Strawberries are important climacteric soft fruit crop widely grown in the world, adapted in geographically diverse area (Biswas et al. 2008). In Bangladesh there is no statistics about the area and production of this crop, since it has recently been introduced into the country. Growers' level extension of strawberry farming can bring a new horizon to the agriculture sector in Bangladesh. There has been a bright prospect of farming strawberry, a high-value crop, everywhere in the country except the coastal districts. Strawberry farming has started gain in popularity in northern region for the last couple of years. Many fresh initiatives have been taken to develop the trade in Panchagarh, Dinajpur, Tangail, Rangpur, Kurigram, Mymensingh, Noakhali, Laxmipur, Jessore, Magura, Faridpur, Madaripur and Dhaka district of Bangladesh (Anon. 2009).

${ }^{1}$ Department of Genetics and Plant Breeding, Bangabandhu Sheikh Mujibur Rahman Agricultural University, Gazipur-1706, Bangladesh. ${ }^{2}$ Department of Botany, University of Dhaka, Dhaka-1000, Bangladesh. *Department of Botany, Barisal University, Barisal. 
There are more than 20 Fragaria species and numerous cultivars commercially cultivated in several countries (Gaafar and Sarker 2006). A germplasm collection with good variability for the desirable characters is the basic requirement of any crop improvement program (Singhania et al. 2006). In addition, crop improvement is primarily based on extensive evaluation of germplasm. Molecular and morphological characters of a plant are most important for nature as well as yield of a crop. Hence, studies about these important traits are necessary for successful cultivation of this crop in a new area like Bangladesh. In Bangladesh, some varietal trials of strawberry (Hossan et al. 2013) have been conducted but the number of sustainable strawberry cultivars is absent for the country's climate. Molecular markers have been developed as a powerful tool to analyze genetic relationships and genetic diversity. As an extension to the variety of existing techniques using polymorphic DNA markers, the Random Amplified Polymorphic DNA (RAPD) technique may be used in to determine the genetic relationships of different crops (Hasan and Raihan 2015). So, the present study has been planned to find out the variations at molecular level of the newly introduced strawberry genotypes in Bangladesh.

\section{Materials and Methods}

The following ten genotypes were used for polymorphism study: $\mathrm{V}_{1}-\mathrm{FA} 006, \mathrm{~V}_{2}-$ BARI strawberry 1, V3- FA 015, V4-FA 024, V5- FA 016, V6- FA 005, V7- FA 007, V8FA 008, V9- FA 023 and V10- FA 017.

$D N A$ extraction and RAPD amplification: DNA was isolated using the modified CTAB method and DNA samples were evaluated both quantitatively and qualitatively using spectrophotometer (SPECORD 50, Analytikjena, Germany) at $260 \mathrm{~nm}$ and agarose gel electrophoresis, respectively. Then, RAPD amplification reactions were performed in a total volume of $25 \mu \mathrm{l}$ mixing with $2.5 \mu \mathrm{l}$ Taq Buffer A10X (Tris with $15 \mathrm{mM} \mathrm{MgCl}$ ), $0.5 \mu \mathrm{l}$ dNTPs $2.5 \mathrm{mM}, 0.2 \mu \mathrm{l}$ Taq DNA polymerase $5 \mathrm{U} / \mu \mathrm{l}, 1.0 \mu \mathrm{l}$ primer, $19.8 \mu \mathrm{l}$ sterile deionized distilled water and 1.0 $\mu \mathrm{LNA}$ template. The results obtained with this primer were later confirmed by six other standard primers, OPA-02, OPA-03, OPB-05, OPB-06, OPB-11 and OPB 12 (Operon Technologies Inc., Alameda, CA, USA), which yielded satisfying results in the same conditions.

PCR amplification for RAPD: PCR mplifications were carried out in a PerkinElmer thermal cycler 480 (Perkin-Elmer, Milan, Italy). In each thermal cycling a negative control (water instead of template) was included to rule out amplification products due to external contamination. All amplifications were repeated twice for each sample on $1 \%$ agarose gel. The optimum amplification cycle was as follows: 


45 times $\left\{\begin{array}{llll}\text { Initial denaturation } & 94^{\circ} \mathrm{C} & \text { For } & 5 \mathrm{~min} \\ \text { Denaturation at } & 94^{\circ} \mathrm{C} & \text { For } & 1 \mathrm{~min} \\ \text { Annealing at } & 36^{\circ} \mathrm{C} & \text { For } & 30 \mathrm{sec} \\ \text { Extension at } & 72^{\circ} \mathrm{C} & \text { For } & 3 \mathrm{~min} \\ \text { Final extension at } & 72^{\circ} \mathrm{C} & \text { For } & 5 \mathrm{~min}\end{array}\right.$

After completion of cycling programme, the reactions were held at $4^{\circ} \mathrm{C}$.

Electrophoresis of the amplified products and documentation: The amplified products were separated electrophoretically on $1 \%$ agarose gel. The gel was prepared using $1.0 \mathrm{~g}$ agarose powder containing ethidium bromide and $100 \mathrm{ml} 1$ $\times$ TAE buffer. Agarose gel electrophoresis was conducted in $1 \times$ TAE buffer at 50 Volts and $100 \mathrm{~mA}$ for $1.5 \mathrm{hrs}$. One molecular weight marker $1 \mathrm{~kb}$ DNA ladder was electrophoresed alongside the RAPD reactions. DNA bands were observed on UV-transilluminator and photographed by a gel documentation system.

RAPD data analysis: Following electrophoresis, the size of amplification products were estimated by comparing the migration of each amplified fragment with that of a known size fragments of $1 \mathrm{~kb}$ molecular weight marker. All distinct bands or fragments (RAPD marker) were there by given identification numbers according to their position on the gel and scored visually on the basis of their presence (1) or absence (0), separately for each individual varieties and each primer. The scores obtained using all primers in the RAPD analysis were then combined to create a single data matrix. Jaccards similarity and dissimilarity coefficients were then calculated between pairs of tracks and strains were grouped by using the Unweighted Pair Group Method With Arithmetic Averages (UPGMA), with a dendrogram construction utility software.

\section{Results and Discussion}

Despite of an important horticultural crop in the world, little information is available on genetic structure of strawberries. The results obtained from the experiment have been presented and discussed under the following headings.

Primer selection and RAPD pattern: Fourteen primers were initially screened on 10 strawberry genotypes for their ability to produce polymorphic patterns and six primers (OPA-02, OPA-03, OPB-05, OPB-06, OPB-11 and OPB-12) gave reproducible and distinct polymorphic amplified products.

A total of 38 RAPD bands were scored of which 38 (100\%) polymorphic amplification products were obtained by using these arbitrary primers. The size of the amplification products ranged from 250 - $5000 \mathrm{bp}$ (Table 1). The dissimilar 
numbers of bands were generated by primer OPA-02, OPA-03, OPB-05, OPB-06, OPB-11 and OPB-12 (Table 2).

Table 1. RAPD primers with corresponding bands score and their size range together with polymorphic bands observed.

\begin{tabular}{llllcc}
\hline $\begin{array}{l}\text { Primer } \\
\text { code }\end{array}$ & $\begin{array}{l}\text { Sequence } \\
\left(5^{\prime}-3^{\prime}\right)\end{array}$ & $\begin{array}{l}\text { Total No. } \\
\text { of band } \\
\text { scored }\end{array}$ & $\begin{array}{l}\text { Size } \\
\text { range } \\
(\mathrm{bp})\end{array}$ & $\begin{array}{l}\text { No. of } \\
\text { polymorphic band }\end{array}$ & $\begin{array}{l}\text { Proportion of } \\
\text { polymorphic } \\
\text { loci (\%) }\end{array}$ \\
\hline OPA-02 & TGC CGA GCT G & 8 & $600-1500$ & 8 & 100 \\
OPA-03 & AGT CAG CCA C & 8 & $400-2000$ & 8 & 100 \\
OPB -05 & TGC GCC CTT C & 2 & $300-500$ & 2 & 100 \\
OPB -06 & TGC TCT GCC C & 4 & $250-500$ & 4 & 100 \\
OPB -11 & GTA GAC CCG T & 3 & $500-1800$ & 3 & 100 \\
OPB -12 & CCT TGA CGC A & 13 & $300-5000$ & 13 & 100 \\
\hline Total & & 38 & & 38 & 100 \\
Average & & 6.33 & & 6.33 & 100 \\
\hline
\end{tabular}

Table 2. Number of polymorphic bands observed in ten variants of strawberry after PCR amplification with RAPD primers OPA-02, OPA-03, OPB-05, OPB-06, OPB-11 and OPB-12.

\begin{tabular}{lccccccc}
\hline $\begin{array}{l}\text { Strawberry } \\
\text { genotype }\end{array}$ & OPA-02 & OPA-03 & OPB-05 & OPB-06 & OPB-11 & OPB-12 & $\begin{array}{c}\text { Total } \\
\text { bands }\end{array}$ \\
\hline $\mathrm{V}_{1}$ & 2 & 0 & 0 & 2 & 0 & 12 & 14 \\
$\mathrm{~V}_{2}$ & 8 & 3 & 0 & 0 & 1 & 8 & 16 \\
$\mathrm{~V}_{3}$ & 7 & 5 & 0 & 1 & 1 & 3 & 12 \\
$\mathrm{~V}_{4}$ & 0 & 4 & 0 & 1 & 0 & 0 & 5 \\
$\mathrm{~V}_{5}$ & 2 & 5 & 0 & 0 & 0 & 7 & 12 \\
$\mathrm{~V}_{6}$ & 7 & 4 & 0 & 0 & 0 & 0 & 8 \\
$\mathrm{~V}_{7}$ & 7 & 1 & 2 & 0 & 0 & 0 & 8 \\
$\mathrm{~V}_{8}$ & 6 & 1 & 1 & 3 & 0 & 2 & 11 \\
$\mathrm{~V}_{9}$ & 0 & 3 & 0 & 2 & 3 & 3 & 11 \\
$\mathrm{~V}_{10}$ & 0 & 6 & 0 & 1 & 3 & 2 & 8 \\
Total Bands & 39 & 32 & 3 & 10 & 8 & 37 & 129 \\
\hline
\end{tabular}

Maximum number of band (13) was shown by the primer OPB-12 and the minimum number of polymorphic band (2) by the primer OPB-05 followed by the primer OPB-11(3). A total of 129 polymorphic bands were amplified from six RAPD primers. The primers OPA-02, OPA-03, OPB-05, OPB-06, OPB-11 and OPB-12 produced $39,32,3,10,8$ and 37 polymorphic bands, respectively in 10 
variants of strawberry. The present experiment produced 6.33 scorable bands per primer and 6.33 polymorphic bands per primer.

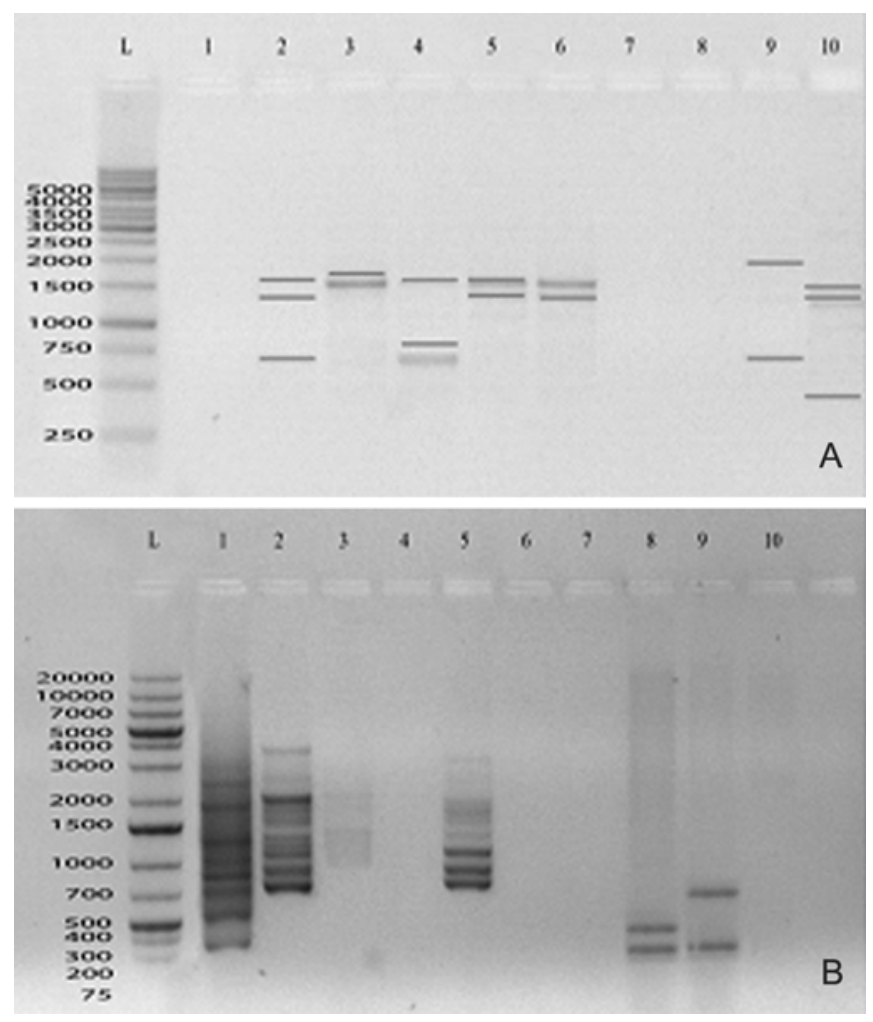

Fig. 1. A RAPD profile of 10 genotypes using primer OPA-03. B. Same as A but using primer OPB-2 OPB-12. L: Molecular weight marker (DNA ladder) Lanes 1-10: 10 genotypes of strawberry..

Genetic distance of the studied genotypes is presented in Table 3. The smaller number of pair-wise differences (high genetic similarity) among some genotypes was likely due to their genetic relatedness. Comparatively higher genetic distance 23.0 was found among $V_{2}$ vs. $V_{9}$. The lowest genetic distance 6.0 was revealed among $V_{6}$ vs. $V_{7}$ as the genotype was morphologically very similar. Considering the genetic distance values, the results indicated that the variants were genetically different from each other which could be used in crop improvement program.

UPGMA dendrogram: Ten variants of Strawberry have been differentiated into two main clusters: $V_{1}, V_{3}, V_{2}, V_{5}$ and $V_{4}, V_{9}, V_{10}, V_{6}, V_{7}, V_{8}$ were grouped in cluster I and cluster II, respectively (Fig. 2). 
Table 3. Genetic distance matrix based on Jaccard coefficient

\begin{tabular}{|c|c|c|c|c|c|c|c|c|c|c|}
\hline & $\mathrm{V}_{1}$ & $\mathrm{~V}_{2}$ & $\mathrm{~V}_{3}$ & $\mathrm{~V}_{4}$ & $\mathrm{~V}_{5}$ & $\mathrm{~V}_{6}$ & $\mathrm{~V}_{7}$ & $\mathrm{~V}_{8}$ & $\mathrm{~V}_{9}$ & $\mathrm{~V}_{10}$ \\
\hline $\mathrm{V}_{1}$ & 0 & 0.667 & 0.815 & 0.950 & 0.696 & 0.920 & 0.917 & 0.792 & 0.826 & 0.923 \\
\hline$V_{2}$ & & 0 & 0.560 & 0.958 & 0.640 & 0.524 & 0.696 & 0.778 & 0.893 & 0.857 \\
\hline$V_{3}$ & & & 0 & 0.833 & 0.750 & 0.579 & 0.632 & 0.682 & 0.826 & 0.727 \\
\hline $\mathrm{V}_{4}$ & & & & 0 & 0.882 & 0.933 & 0.929 & 0.875 & 0.857 & 0.692 \\
\hline $\mathrm{V}_{5}$ & & & & & 0 & 0.684 & 0.909 & 0.920 & 0.913 & 0.762 \\
\hline$V_{6}$ & & & & & & 0 & 0.500 & 0.737 & 0.952 & 0.850 \\
\hline $\mathrm{V}_{7}$ & & & & & & & 0 & 0.562 & 1.000 & 0.952 \\
\hline $\mathrm{V}_{8}$ & & & & & & & & 0 & 0.800 & 0.864 \\
\hline $\mathrm{V}_{9}$ & & & & & & & & & 0 & 0.467 \\
\hline$V_{10}$ & & & & & & & & & & 0 \\
\hline
\end{tabular}

The cluster I was divided into two sub-clusters. In sub-cluster A of cluster I, there was $V_{1}$ and $V_{3}$ and in sub-cluster $B$ of cluster $I_{,} V_{2}$ and $V_{5}$ and their genetic relationship was present between sub-sub clusters.

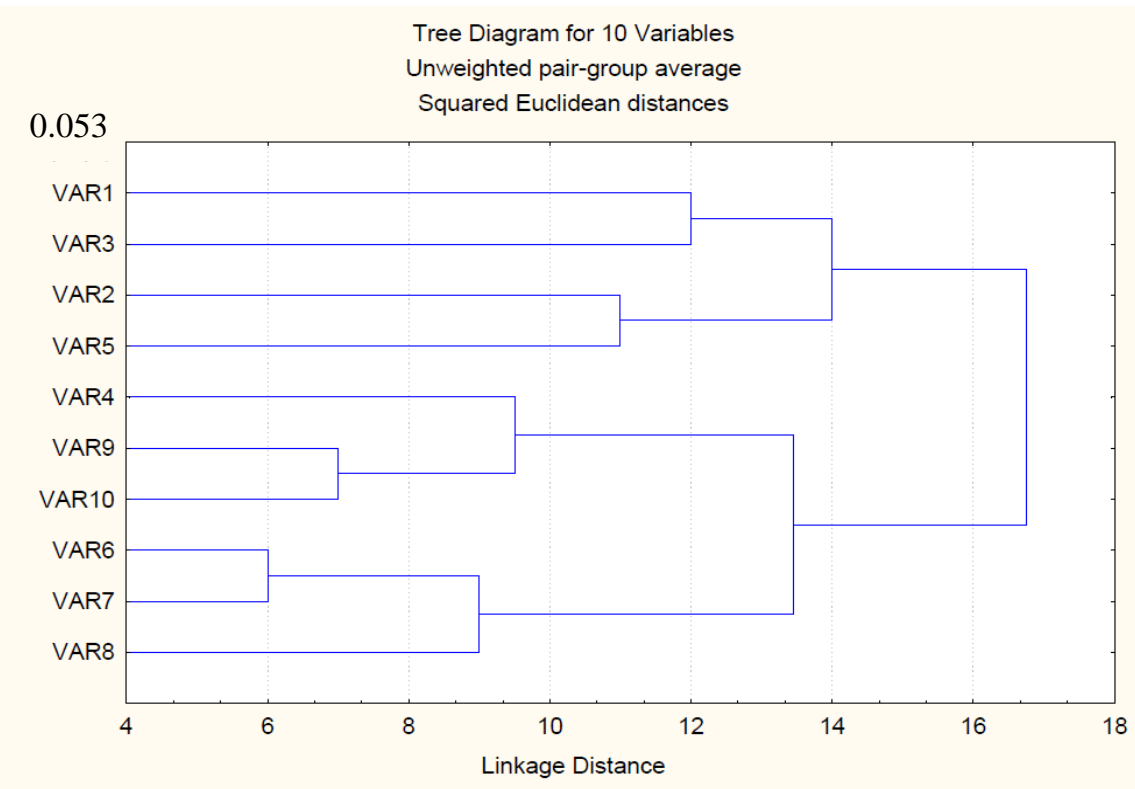

Fig. 2. Unweighted pair group method of arithmetic mean (UPGMA) dendrogram based on Jaccard coefficient, summarizing data on differentiation in 10 genotypes according to RAPD-PCR analysis.

The cluster II was divided into two sub-clusters. In sub-cluster A of cluster II, there was in $\mathrm{V}_{4} ; \mathrm{V}_{9}$ and $\mathrm{V}_{10}$ formed one sub-sub-cluster and in sub cluster B of cluster II, there was in $\mathrm{V}_{6} ; \mathrm{V}_{7}$ and $\mathrm{V}_{8}$ formed another sub-sub-clusters, genetic relationship were present between sub-sub-clusters. 
Genotypic variations based on molecular characterization indicated that genotypes belonging to different clusters depend on their genetic components itself, but not at geographical origin at all. Therefore, it could be concluded that for further research program, especially for hybridization, genotypes selected from different clusters would provide maximum heterosis.

Ten variants of strawberry have been differentiated into two main clusters after molecular characterization. It could be concluded that for further research program, especially for hybridization, genotypes selected from different clusters would provide maximum heterosis regarding the yield.

\section{Acknowledgement}

The research work was done under the Science and Technology Special Grant of Bangladesh. The authors are thankful to Department of Botany, University of Dhaka for providing technical facilities and Department of Pomoloy, Horticulture Research Center, Bangladesh Agricultural Research Institute (BARI) for suggestion and knowledge support.

\section{References}

Anonymous (2009). Strawberry flavours export dream. The Daily Star, 16 January. 2009.

Biswas MK, Islam R and Hossain M (2008) Micropropagation and field evaluation of Strawberry in Bangladesh. Journal of Agricultural Technology 4(1): 167-182.

Gaafar RM and Sarker MM (2006) Monitoring of cultivars identity and genetic stability in strawberry varieties grown in Egypt. or. J. Agri.1 Sci. 2(1): 29-36.

Hasan M and Raihan MS (2015) Genetic variability in bangladeshi aromatic rice through RAPD analysis. Turkish J. Agril. - Food Sc. Technol. 3(3): 107-111.

Hossan MJ, Islam MS, Ahsan MK, Mehraj H and Uddin AFMJ (2013) Growth and yield performance of strawberry germplasm at Sher-e-Bangla Agricultural University. Journal of Experimental Biosciences. 4(1): 89-92.

Singhania DL, Singh D and Raje RS (2006) Coriander. In: Ravindran, P. R. K. N. Babu, K.N. Shiva and J. A. Kallupurackal (eds.). Advances n Spices and Achievements of Spices Research in India. grobios, Agro House, Chopasani Road, Jodhpur. 342002. pp. 678-695. 